\title{
Synthesis and Comparative Antibacterial Activity of Fatty Acid Capped Silver Nanoparticles
}

\author{
Rama Sharma \\ Department of Biotechnology, GLA University, Mathura - 281 406, Uttar Pradesh, India.
}

\begin{abstract}
In the present work, the chemical reduction method has been used to synthesize silver nanoparticles using stearic acid capping agents in different concentrations. These nanoparticles are characterized by ultraviolet-visible spectroscopy and dynamic light scattering (DLS). The size of the synthesized silver nanoparticles found between $80-100 \mathrm{~nm}$ and stable up to 5 months. These nanoparticles show a very good bactericidal influence on $E$. coli and $S$. aureus. In this method silver nanoparticles have synthesized at room temperature without using any inert atmosphere, this is the advantage of this method over others.
\end{abstract}

Keywords: Silver nanoparticles, Stearic acid, UV-Vis. spectroscopy, Antibacterial

*Correspondence: dr.rama76@gmail.com

(Received: April 12, 2020; accepted: August 26, 2020)

Citation: Sharma R. Synthesis and Comparative Antibacterial Activity of Fatty Acid Capped Silver Nanoparticles. J Pure Appl Microbiol. 2020;14(3):1941-1947. doi: 10.22207/JPAM.14.3.33

(C) The Author(s) 2020. Open Access. This article is distributed under the terms of the Creative Commons Attribution 4.0 International License which permits unrestricted use, sharing, distribution, and reproduction in any medium, provided you give appropriate credit to the original author(s) and the source, provide a link to the Creative Commons license, and indicate if changes were made. 


\section{INTRODUCTION}

Nanotechnology, at this time, is a prominent field which is used for the production of nanomaterials and their utilisation ${ }^{1}$ Persimmon, Ginkgo, Magnolia and Platanus. Chemical reduction method to synthesize silver nanoparticles reduces atomic silver $\left(\mathrm{Ag}^{+}\right)$of silver nitrate to zero-valent silver $\left(\mathrm{Ag}^{\circ}\right)$ i.e. nanosilver. Silver nanoparticles having $1 \mathrm{~nm}$ and $100 \mathrm{~nm}$ size have good medicinal properties ${ }^{2}$. Silver compounds are very well known antimicrobial agents from ancient times. These are toxic also for several bacteria ${ }^{3,4}$. Because of these applications, silver is frequently used and has an important role in the medical field.

Silver nanoparticles are more and more used in different areas, together with health care, food, and manufacturing purposes, because of their exclusive properties. These contain visual, thermal, high electrical conductivity, and biological properties. These properties of silver nanoparticles make them useful as biological sensors. Silver nanoparticles are used as an antibacterial, antiviral, antifungal coating ${ }^{5}$. Nowadays biomedical devices containing silver nanoparticles, liberate low levels of silver ions continuously to give protection from bacteria.

Silver nanoparticles can be reduced by reducing agents like sodium borohydride in the presence of fatty acids like myristic acid at room temperature in a medium containing methanol-water. Fatty acids are long-chain lipids with hydrocarbon compounds and carboxylic groups on the terminal. It has been investigated that $\mathrm{pH}$ increases the visual properties of silver nanoparticles. The silver nanoparticle that is capped by fatty acid namely myristic acid are 3 to 7 nanometer in size and has stability for several months. This way of synthesis of myristic acid could be beneficial more than the last information of carboxylate stabilize silver nanoparticles. The benefits of this method include the production of silver nanoparticles at room temperature in aqueous medium ${ }^{6}$. Das et al. ${ }^{7}$ prepared the silver nanoparticle by using ethanol in the presence of sodium linoleate through the reduction method. They reported that nanoparticle stops the growth of microorganisms like bacteria, fungi, parasites, etc.

Rao and Trivedi prepared some fatty acid stabilized silver nanoparticles by biphasic synthesis using three reducing agents like triethanolamine, formaldehyde, and dimethyl amide ${ }^{8}$. They found the role of experimental condition on the size of particles. It has been found that as the fatty acid chain length is increased, the stability of silver nanoparticles is also increased. The several experimental conditions like concentration and temperature inclined the dimension of silver nanoparticles frequently.

Cinar et al. prepared silver nanoparticles by oleylamine and reduction of oleic acid. They reported the use of these nanoparticles for the manufacturing of nano cable through coaxial electrospinning ${ }^{9}$. Different fatty acid capped silver nanoparticles were prepared by different methods ${ }^{10-16}$. Silver nanoparticles have good applications in different fields ${ }^{17-22}$.

Industrial applications of silver nanoparticles are very limited because they get easily oxidized during formation. To overcome such type of problems, fatty acids and their compounds have been used as stabilizers to synthesize metal nanoparticles ${ }^{23}$. Generally, fatty acids are well known to coordinate with metal nanoparticles ${ }^{24,25}$.

\section{EXPERIMENTAL \\ MATERIALS}

All the chemicals used in the experiment were from Central Drug House, India. Triple distilled water is used for making all the solutions. Analytical reagent (AR) grade reagents and solvents are used to perform this work.

\section{Synthesis of silver nanoparticles (AgNPs)}

In this work silver nitrate $\left(\mathrm{AgNO}_{3}\right)$ was reduced to get AgNPs using hydrazine hydrate and stearic acid aqueous solution ${ }^{12}$. A solution of stearic acid was prepared by different concentrations of stearic acid ( $1 \mathrm{~g}, 0.6 \mathrm{~g}, 0.3 \mathrm{~g}$ ). Each of these concentrations of stearic acid was dissolved in $50 \mathrm{ml}$ triple distilled water separately and stirred for 10 minutes at $80^{\circ} \mathrm{C}$ to obtain a clear solution. Then add $1.2 \mathrm{ml}$ of liquor $\mathrm{NH}_{3}$ in this solution and stir this solution by using a magnetic stirrer for about 10 minutes. After stirring add 0.5 grams of silver nitrate, stir for about 5 minutes, and add $4 \mathrm{ml}$ hydrazine hydrate dropwise. Stirring was continued for 1 hour to get a transparent solution. Then centrifugation was done so that supernatant and pallet of silver nanoparticles separated. 


\section{Physicochemical characterization}

Initially, the synthesis of AgNPs (diluted 10 times with triple distilled water) was established by absorption spectra at the wavelength of 200-600 nm. The automatic mode was followed to determine the size of AgNPs with the technique Dynamic light scattering using instrument Zetasizer Nano ZS (Malvern Instruments, UK).

\section{Antibacterial Activity \\ Preparation of Media}

The standard formulation given in Bacteriology Manual ${ }^{26}$ was followed for the preparation of all media.

\section{Composition}

- peptone - $0.5 \%$

- $\mathrm{NaCl}-0.5 \%$

- agar $-1.5 \%$

- beef extract - $0.3 \%$

- distilled water

- $\mathrm{pH}-(6.8)$ at room temparature.

All the above ingredients were completely dissolved in triple distilled water. This medium was taken into a flask and this flask was autoclaved for 30 minutes at $121^{\circ} \mathrm{C}$ for sterilization. $15 \mathrm{ml}$ of this sterilized medium was poured in sterilized Petri plates aseptically and incubated for about 24 hours at $37^{\circ} \mathrm{C}$.

Antibacterial activities of AgNPs were performed by the disc diffusion technique. The prepared AgNPs were tested against the antibacterial resistance $E$. coli (gram -ve) and $S$. aureus (gram +ve). $10 \mu \mathrm{l}$ of E. coli and $10 \mu \mathrm{l}$ of $S$. aureus were spread into the nutrient agar medium plates. The swab was used to spread the smear evenly.

Sterile discs were prepared by dipping in $1 \mathrm{mM} \mathrm{AgNO}_{3}$ solution, nano colloidal solution synthesized by $0.3 \mathrm{~g}, 0.6 \mathrm{~g}$, and $1 \mathrm{~g}$ stearic acid. The so prepared 4 sterile discs were placed in the $E$. coli culture plate and 4 were placed in the $S$. aureus culture plate to observe the zone of inhibition. All culture plates were gestated for about 24 hours at $37^{\circ} \mathrm{C}$ and the region of inhibition was measured in $\mathrm{mm}$.

\section{RESULTS AND DISCUSSION}

\section{Synthesis of silver nanoparticles}

The color change of the solution from light brown to dark brown (Fig. 1) approves the synthesis of AgNPs and the absorption band at around $420 \mathrm{~nm}$ also confirms the synthesis of AgNPs in the suspension.

\section{Physicochemical characterization}

Some factors like concentration affect the synthesis of small-sized monodispersed nanoparticles. So it is necessary to optimize different concentrations of stearic acid solutions for the synthesis of AgNPs. The synthesis of AgNPs

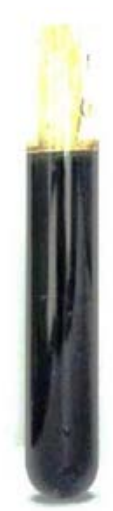

Fig. 1. AgNPs

at a concentration of $0.3 \mathrm{~g} / 50 \mathrm{ml}$ showed maximum absorbance. The reduction was continued for 60 minutes and a characteristic surface plasma resonance band was noticed around $420 \mathrm{~nm}$, which confirms the formation of AgNPs (Fig. 2).

Metal nanoparticles having surface plasma resonance(SPR) can easily be characterized by absorption spectra. The SPR takes place

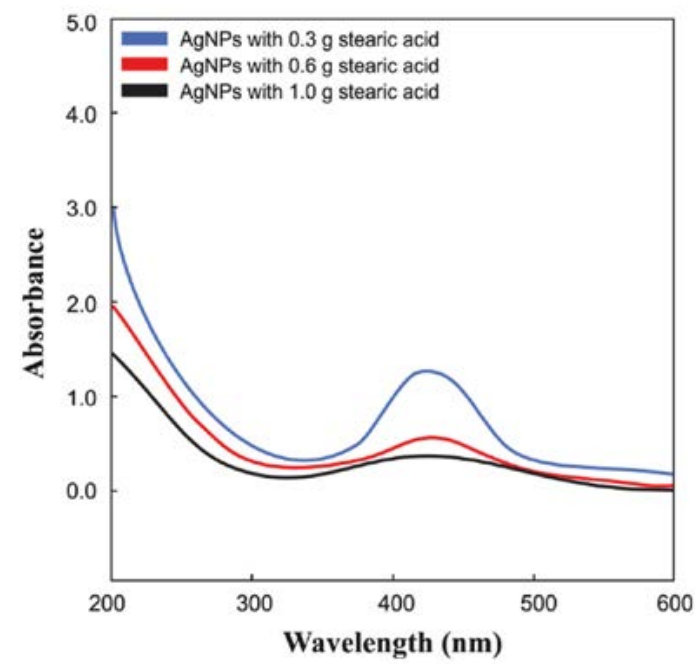

Fig. 2. UV-Vis spectra 
because of the fluctuation of the electrons present on the surface of metal nanoparticles due to the external energy sources. By this specific SPR peak, the physical nature of nanoparticles can be studied very easily.SPR mainly depends upon the size of nanoparticles and the properties of dielectric medium ${ }^{27-29}$. The broadband shows broad size and aggregation of nanoparticles while a narrow band

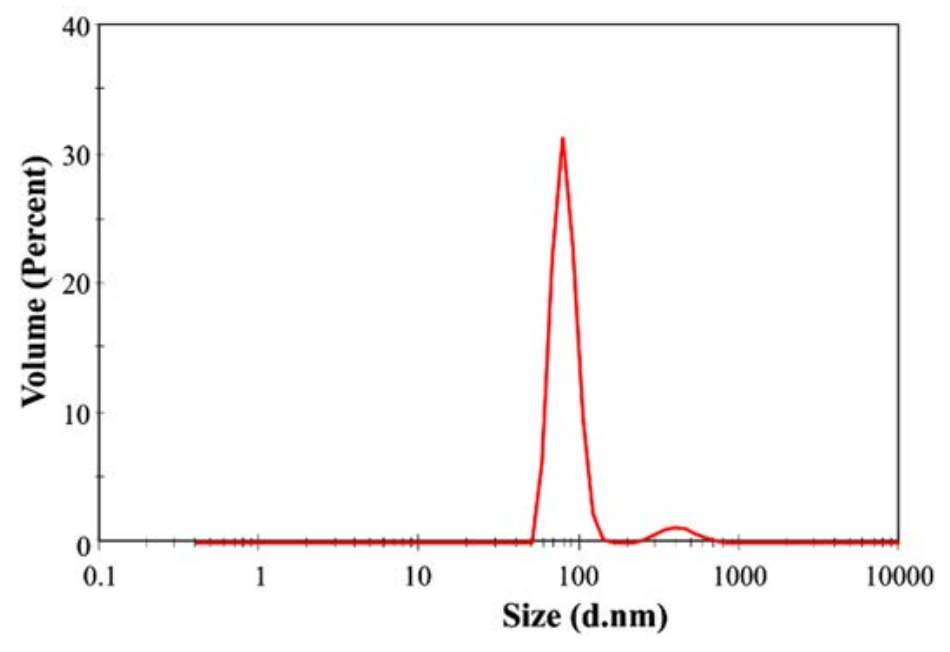

Fig. 3. Particle size analysis

denotes monodispersed particles ${ }^{30}$. A sharp band represents the narrow distribution of the $\mathrm{AgNPs}^{31}$. The position and number of peaks also change with the shape and size of nanoparticles.

Spherical nanoparticles show a particular SPR band and anisotropic particles show more than two SPR bands ${ }^{32}$. The size of the synthesized

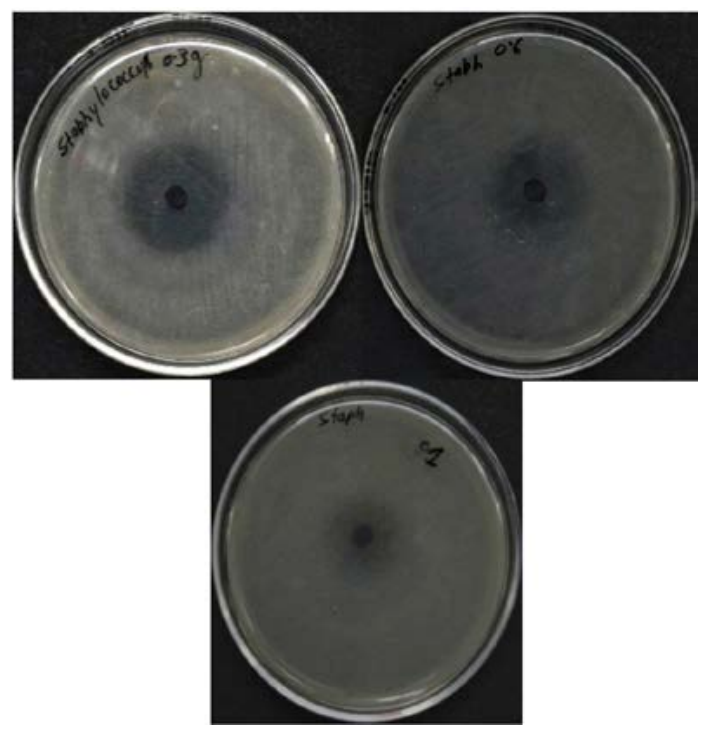

Fig. 4(a). Zone of inhibition against $S$. aureus

Journal of Pure and Applied Microbiology

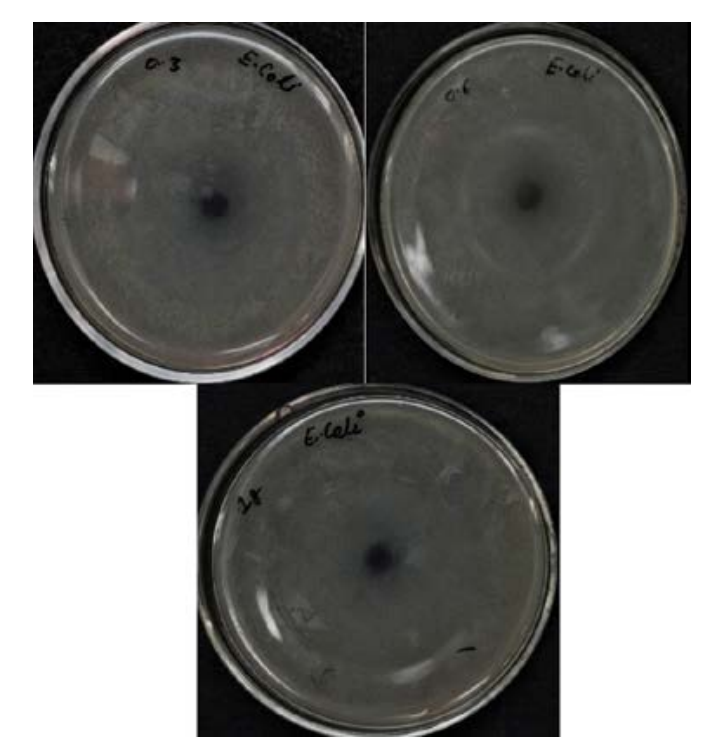

Fig. 4(b). The zone of inhibition against E. coli

nanoparticles was analyzed by dynamic light scattering. In the DLS technique, the size is measured by illuminating the nanoparticles in Brownian motion by a laser beam. The light scattered by the nanoparticles is then analyzed by the auto-correlator. The synthesized AgNPs were 80-100 $\mathrm{nm}$ in size (Fig. 3).

44 www.microbiologyjournal.org 
Table 1. Zone of inhibition

\begin{tabular}{lcc}
\hline $\begin{array}{l}\text { AgNPs with different } \\
\text { concen. of stearic acid } \\
\text { (in gram) }\end{array}$ & $\begin{array}{c}\text { E. coli } \\
\text { (in mm) }\end{array}$ & $\begin{array}{c}\text { S. aureus } \\
\text { (in mm) }\end{array}$ \\
\hline 0.3 & 20 & 6 \\
0.6 & 12 & 4 \\
1 & 6 & 2 \\
1 mM AgNO3 & 1 & 1 \\
\hline
\end{tabular}

\section{Antibacterial activity}

Larger surface area is favorable for bacterial surface interactions that are the reason silver nanoparticles show better antibacterial activities than silver ions. As the particle size decreases (nanoscale), surface area increases which facilitate bacterial action ${ }^{33}$. The zone of inhibition obtained against $E$. coli and $S$. aureus clearly mentions the influential nature of synthesized AgNPs (Table 1). A noticeable difference in the zone of inhibition was observed for each solution having a different amount of stearic acid as shown in Fig.s $4 a$ and 4b. Different researchers reported a number of mechanisms for the antibacterial action of AgNPs ${ }^{34-36}$.

\section{The stability of silver nanoparticles}

Silver nanoparticles have many applications because of their stability. If silver nanoparticles so obtained show precipitation after storage, the number of applications will be reduced. The silver nanoparticles colloid fresh and after storage of 5 months are shown in Fig. 5. No precipitation was noticed in the colloidal solution of so obtained stearic acid stabilized silver nanoparticles even after storage for a long time, so it becomes clear that stearic acid is a good stabilizing agent to impart stability to silver nanoparticles. Precipitation and oxidation of silver nanoparticles are prevented by the high surface activity, involving organic functional groups of stearic acid.

\section{CONCLUSION}

Hydrazine hydrate and stearic acid are used as a reducing agent to reduce silver nitrate to silver nanoparticles. It is successfully established that stearic acid is a good coating agent to synthesize AgNPs in a suspension. The so prepared

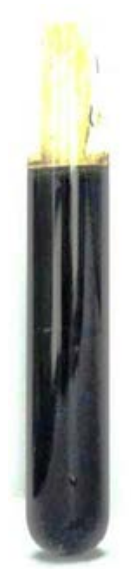

(a)

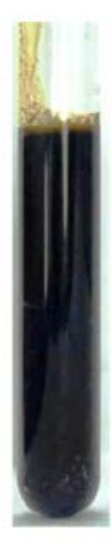

(b)
Fig. 5. AgNPs (a) fresh (b) after 5 months

silver nanoparticles showed good stability and no precipitation was observed after storage of 5 months and longer. It is clear from the zone of inhibition that the concentration affects the zone of inhibition as the concentration of capping agent i.e. stearic acid increased, the zone of inhibition decreased.

\section{ACKNOWLEDGMENTS}

Author is thankful to the Director, IAH, G.L.A. University, Mathura for financial support of this research.

\section{FUNDING}

None.

\section{ETHICS STATEMENT}

Not applicable.

\section{DATA AVAILABILITY}

All the analysis related to this work are incorporated in the manuscript.

\section{REFERENCES}

1. Song JY, Kim BS. Rapid biological synthesis of silver nanoparticles using plant leaf extracts. Bioprocess Biosyst Eng. 2009;32(1):79-84. doi: 10.1007/s00449-008-0224-6

2. Li W-R, Xie X-B, Shi Q-S, Zeng H-Y, Ou-Yang Y-S, Chen $Y-B$. Antibacterial activity and mechanism of silver nanoparticles on Escherichia coli. Appl Microbiol Biotechnol. 2010;85(4):1115-1122. doi: 10.1007/s00253-009-2159-5 
3. Slawson RM, Trevors JT, Lee H. Silver accumulation and resistance in Pseudomonas stutzeri. Arch Microbiol. 1992;158(6):398-404. doi: 10.1007/BF00276299

4. Zhao G, Stevens SE. Multiple parameters for the comprehensive evaluation of the susceptibility of Escherichia coli to the silver ion. BioMetals. 1998;11(1):27-32. doi: 10.1023/A:1009253223055

5. Gupta N, Gupta C, Sharma S, Sharma RK, Bohidar HB Comparative study of antibacterial activity of standard antibiotic with silver nanoparticles synthesized using ocimum tenuiflorum and garcinia mangostana leaves. Chem Biol Lett. 2015;2(2):41-44.

6. Agasti N, Kaushik NK. Myristic acid capped silver nanoparticles: aqueous phase synthesis and $\mathrm{pH}$ induced optical properties. J Chinese Adv Mater Soc. 2014;2(1):31-39. doi: 10.1080/22243682.2014.893411

7. Das R, Gang S, Nath SS. Preparation and Antibacterial Activity of Silver Nanoparticles. J Biomater Nanobiotechnol. 2011;02(04):472-475. doi: 10.4236/ jbnb.2011.24057

8. Rao CRK, Trivedi DC. Biphasic synthesis of fatty acids stabilized silver nanoparticles: Role of experimental conditions on particle size. Mater Chem Phys. 2006;99(2-3):354-360. doi: 10.1016/j. matchemphys.2005.11.004

9. Cinar S, Gunduz G, Mavis B, Colak U. Synthesis of silver nanoparticles by oleylamine-oleic acid reduction and its use in making nanocable by coaxial electrospinning. J Nanosci Nanotechnol. 2011;11(4):3669-3679. doi: 10.1166/jnn.2011.3812

10. Khanna PK, Kulkarni D, Beri RK. Synthesis and characterization of myristic acid capped silver nanoparticles. J Nanoparticle Res. 2008;10(6):10591062. doi: 10.1007/s11051-008-9366-3

11. Le AT, Tam LT, Tam PD, et al. Synthesis of oleic acidstabilized silver nanoparticles and analysis of their antibacterial activity. Mater Sci Eng C. 2010;30(6):910916. doi: 10.1016/j.msec.2010.04.009

12. Dong $\mathrm{C}$, Zhang $\mathrm{X}$, Cai H, et al. Synthesis of stearic acidstabilized silver nanoparticles in aqueous solution. Adv Powder Technol. 2016;27(6):2416-2423. doi: 10.1016/j.apt.2016.08.018

13. Wang W, Chen X, Efrima S. Silver nanoparticles capped by long-chain unsaturated carboxylates. J Phys Chem B. 1999;103(34):7238-7246. doi: 10.1021/jp991101q

14. El Fatah Hamouda RA, El-Mongy MA, Eid KF. Antibacterial activity of silver nanoparticles using ulva fasciata extracts as reducing agent and sodium dodecyl sulfate as stabilizer. Int J Pharmacol. 2018;14(3):359368. doi: 10.3923/ijp.2018.359.368

15. Noritomi H, Umezawa Y, Miyagawa S, KatoS. Preparation of Highly Concentrated Silver Nanoparticles in Reverse Micelles of Sucrose Fatty Acid Esters through Solid-Liquid Extraction Method. Adv Chem Eng Sci. 2011;01(04):299-304. doi: 10.4236/aces.2011.14041

16. Rao CRK, Trivedi DC. Synthesis and characterization of fatty acids passivated silver nanoparticles - Their interaction with PPy. In:Synthetic Metals. 2005;155:324327. doi: 10.1016/j.synthmet.2005.01.038

17. Murphy $M$, Ting $K$, Zhang $X$, Soo $C$, Zheng $Z$. Current development of silver nanoparticle preparation, investigation, and application in the field of medicine. J Nanomater. 2015;2015:1-12. doi: 10.1155/2015/696918

18. Zhang XF, Liu ZG, Shen W, Gurunathan S. Silver nanoparticles: Synthesis, characterization, properties, applications, and therapeutic approaches. Int J Mol Sci. 2016;17(9):1-34. doi: 10.3390/ijms17091534

19. Wen L, Zeng P, Zhang L, Huang W, Wang H, Chen G. Symbiosis theory-directed green synthesis of silver nanoparticles and their application in infected wound healing. Int J Nanomedicine. 2016;11:2757-2767. doi: 10.2147/IJN.S106662

20. Niska K, Knap N, Kedzia A, Jaskiewicz M, Kamysz W, Inkielewicz-Stepniak I. Capping agent-dependent toxicity and antimicrobial activity of silver nanoparticles: An in vitro study. concerns about potential application in dental practice. Int J Med Sci. 2016;13(10):772-782. doi: 10.7150/ijms.16011

21. Vijayaraj R, Kumar GD, Kumaran NS. In vitro antiinflammatory activity of silver nanoparticle synthesized Avicennia marina (Forssk.) Vierh.: A green synthetic approach. Int J Green Pharm. 2018;12(3):S528-S536.

22. Azocar MI, Tamayo L, Vejar N, et al. A systematic study of antibacterial silver nanoparticles: efficiency, enhanced permeability, and cytotoxic effects. J Nanoparticle Res. 2014;16(9):1-9. doi: 10.1007/ s11051-014-2465-4

23. He S, Chen H, Guo Z, Wang B, Tang C, Feng Y. High-concentration silver colloid stabilized by a cationic gemini surfactant. Colloids Surfaces A Physicochem Eng Asp. 2013;429:98-105. doi: 10.1016/j.colsurfa.2013.03.068

24. Lee KJ, Lee Y II, Shim IK, Joung J, Oh YS. Direct synthesis and bonding origins of monolayer-protected silver nanocrystals from silver nitrate through in situ ligand exchange. J Colloid Interface Sci. 2006;304(1):92-97. doi: 10.1016/j.jcis.2006.08.037

25. Shim IK, Lee Y II, Lee KJ, Joung J. An organometallic route to highly monodispersed silver nanoparticles and their application to ink-jet printing. Mater Chem Phys. 2008;110(2-3):316-321. doi: 10.1016/j. matchemphys.2008.02.020

26. Aneja KR. Experiments in Microbiology, Plant Pathology and Biotechnology. New Age International. 2003.

27. Nath SS, Chakdar D, Gope G. Synthesis of CdS and ZnS quantum dots and their applications in electronics. Nanotrends. 2007;2(3):20-28.

28. Taleb A, Petit C, Pileni MP. Optical properties of self-assembled 2D and 3D superlattices of silver nanoparticles. J Phys Chem B. 1998;102(12):22142220. doi: 10.1021/jp972807s

29. Noginov MA, Zhu G, Bahoura M, et al. The effect of gain and absorption on surface plasmons in metal nanoparticles. Appl Phys B Lasers Opt. 2007;86(3):455460. doi: 10.1007/s00340-006-2401-0

30. Bohren CF, Huffman DR. Absorption and Scattering by a Sphere. Absorpt Scatt Light by Small Part. 2007:82129.doi: 10.1002/9783527618156.ch4

31. He S, Yao J, Jiang $P$, et al. Formation of silver nanoparticles and self-assembled two-dimensional ordered superlattice. Langmuir. 2001;17(5):15711575. doi: 10.1021/la001239w 
32. Newman P. Contributions to the optics of turbid media, particularly of colloidal metal solutions. Ann Phys. 1908;25(3):377-445.

33. Rai M, Yadav A, Gade A. Silver nanoparticles as a new generation of antimicrobials. Biotechnol Adv. 2009;27(1):76-83. doi: 10.1016/j. biotechadv.2008.09.002

34. Duran N, Duran $M$, de Jesus $M B$, Seabra $A B$, Favaro WJ, Nakazato G. Silver nanoparticles: A new view on mechanistic aspects on antimicrobial activity. Nanomedicine Nanotechnology, Biol Med. 2016;12(3):789-799. doi: 10.1016/j.nano.2015.11.016
35. Duran N, Marcato PD, De Conti R, Alves OL, Costa FTM, Brocchi M. Potential use of silver nanoparticles on pathogenic bacteria, their toxicity and possible mechanisms of action. J Braz Chem Soc. 2010;21(6):949-959. doi: 10.1590/S010350532010000600002

36. Lok CN, Ho CM, Chen R, et al. Proteomic analysis of the mode of antibacterial action of silver nanoparticles. J Proteome Res. 2006;5(4):916-924. doi: 10.1021/ pr0504079 